\title{
Uma matriz ética nos protocolos de combate à COVID-19 na prática odontológica: revisão narrativa
}

\author{
An ethical matrix in the protocols to combat COVID-19 in dental practice: narrative review
}

\author{
Una matriz ética em los protocolos para combatir el COVID-19 em la práctica dental: \\ revisión narrativa
}

Ricardo Rodrigues Werneck ${ }^{1 *}$, Talita Cerdeira Werneck², Maria da Conceição Azevedo ${ }^{3}$.

\begin{abstract}
RESUMO
Objetivo: Verificar se os protocolos de combate à COVID-19 incluem uma matriz ética subjacente às condutas recomendadas aos profissionais de odontologia na prática clínica. Revisão Bibliográfica: É urgente a implementação de protocolos rigorosos e eficientes no controle de infecções, entretanto são necessárias preocupação e inquietação com a condição do outro, numa atitude de responsabilização ou corresponsabilização com a condição desfavorável em que ele se encontra. A esta responsabilidade entendese predisposição ao preparo adequado para o oferecimento do que há de melhor a serviço daquele que receberá o cuidado. Assim como cada indivíduo se interroga no seu agir quotidiano sobre a parcela de bem das suas ações, também em cada coletivo profissional a dimensão ética corresponde a se perguntar qual a sua contribuição ao bem comum. Considerações Finais: Foi possível verificar nos protocolos, preocupações éticas dos profissionais, o que, se não podem ser consideradas como reveladoras de uma matriz de concepção ética, certamente já demonstram sinais da competência ética na elaboração de condutas frente ao coronavírus.
\end{abstract}

Palavras-chave: Coronavírus, Ética, Odontologia, Controle de infecções.

\begin{abstract}
Objective: Verify that the protocols to combat COVID-19 include an ethical matrix underlying the conduct recommended for dental professionals in clinical practice. To evaluate the protocols to combat COVID-19 through narrative review, in order to verify whether there is an ethical matrix corresponding to permeate the conducts recommended to dental professionals in clinical practice. Bibliographic Review: It is urgent to implement rigorous and efficient protocols for infection control, however, concern and concern about the condition of the other is necessary, in an attitude of responsibility or co-responsibility with the unfavorable condition in which he finds himself. This responsibility is understood as predisposition to the adequate preparation for offering the best in the service of the one who will receive the care. Just as each individual wonders in their daily actions about a portion of the good of their actions, so in each professional group the ethical dimension corresponds to the question os their contribution to the common good. Final Considerations: It was possible to verify in the protocols, ethical concerns of professionals, which, if they cannot be considered as revealing an array of ethical conception, certainly already show signs of ethical competence in the elaboration of conducts against the coronavirus.
\end{abstract}

Keywords: Coronavirus, Ethics, Dentistry, Infection control.

\footnotetext{
${ }^{1}$ Universidade Federal de Juiz de Fora (UFJF), Juiz de Fora - MG.

*E-mail: ricardo.rodrigues.werneck@hotmail.com

2 Faculdade de Ciências Médicas e da Saúde de Juiz de Fora (SUPREMA), Juiz de Fora - MG.

3 Universidade de Trá-os-Montes e Alto Douro (UTAD), Vila Real - Portugal.
} 


\section{RESUMEN}

Objetivo: Verificar que los protocolos para combatir COVID-19 incluyan una matriz ética subyacente a la conducta recomendada para los profesionales dentales en la práctica clínica. Revisión Bibliográfica: Es urgente implementar protocolos rigurosos y eficientes para el control de infecciones, sin embargo, es necesaria la preocupación y preocupación por la condición del otro, en una actitud de responsabilidad o corresponsabilidad con la condición desfavorable en la que se encuentra. Esta responsabilidad se entiende como predisposición a la adecuada preparación para ofrecer lo mejor en el servicio de quien recibirá la atención. Así como cada individuo se pregunta en sus acciones diarias sobre la participación del bien en sus acciones, así en cada grupo profesional la dimensión ética corresponde a preguntarse cuál es su contribuición al bien común. Consideraciones Finales: Se pudo constatar en los protocolos, inquietudes éticas de profesionales, que, si no pueden ser consideradas como reveladoras de un conjunto de concepciones éticas, ciertamente ya muestran signos de competencia ética en la elaboración de conductas contra el coronavirus.

Palabras clave: Coronavirus, Ética, Odontología, Control de infecciones.

\section{INTRODUÇÃO}

O surto de um novo coronavírus está a provocar preocupação entre os profissionais de saúde em todo o mundo, por apresentar comportamento imprevisível e ser muito virulento.Trata-se do $\beta$-coronavírus (2019$\mathrm{nCoV}$ ), encontrado em um mercado de frutos do mar da cidade de Wuhan, província de Hubei, China, que se espalhou rapidamente para outras províncias da própria China e de outros países (XIAN P, et al., 2020).

A Organização Mundial de Saúde (OMS) declarou, em 30 de janeiro de 2020, que este surto de coronavírus constitui uma emergência de saúde pública de importância internacional, o mais alto nível de alerta da Organização. Já em 11 de março de 2020, a Doença do Coronavírus - 2019 (COVID-19) foi caracterizada como uma pandemia. Até o dia 21 de agosto de 2020 foram confirmados mais de 22 milhões de casos no mundo e 789.000 mortes causadas por este vírus. No Brasil o total de mortes ultrapassa a marca de 110.000, e mais de 3 milhões e meio de casos da doença (WORLD HEALTH ORGANIZATION, 2020).

Foram formuladas várias hipóteses quanto à origem deste microorganismo, sendo a mais comumente aceite a que aponta para um vírus quimérico, entre um coronavírus de morcego e outro de origem desconhecida. O morcego seria o reservatório do 2019-nCoV, transmitido ao ser humano via pangolim, mamífero encontrado na África e na Ásia. Além desta hipótese, aventou-se também a possibilidade de uma manipulação laboratorial queresultasse um novo vírus. Entretanto, há que se aguardar novas pesquisas, com resultados mais conclusivos (DUARTE PM, 2020).

Os principais sintomas clínicos desta doença são: febre, tosse seca, espirros, falta de ar, mialgias, distúrbios no paladar e no olfato e catarro. As gotículas emitidas pela fala e pela tosse, assim como o contato físico são as principais vias de disseminação (TUÑAS ITC, et al., 2020; PENG S, et al., 2020).

Diante deste cenário, o cirurgião-dentista, ao ter contato direto com a boca do paciente e especialmente a saliva, um dos principais meios de transmissão, tem grande risco de infectar-se a si próprio, aos auxiliares de saúde bucal e aos pacientes, a considerar que os aerossóis originados pelas turbinas, jatos de bicarbonato, ultrasson e seringa tríplice, utilizados nos atendimentos, podem contaminar todo o ambiente, elevandoainda mais o risco de contaminação (MORALES-NAVARRO D, 2020).

O mecanismo de contaminação está baseado na ligação da proteína $S$ do coronavírus a receptores do hospedeiro, de forma a facilitar a entrada do vírus nas células-alvo. O 2019-nCoV, neste caso, se liga à Enzima Conversora de Angiotensina 2 humana (ACE2).Na ausência desta Enzima não existe possibilidade de haver ligação. $A$ alta afinidade entre ACE2 e a proteína $S$ do 2019-nCoV também sugere que a população com maior expressão de ACE2 poderia ser mais suscetível a 2019-nCoV. Reside aí o risco de infecção do profissional de odontologia, porque ACE2 está abundantemente presente em todo o trato respiratório, bem como no epitélio dos ductos das glândulas salivares. Células epiteliais ACE2 de ductos de glândulas salivares são uma classe de alvos precoces da infecção por coronavírus (HAO X, et al., 2019). 
Desta forma, tendo em vista a importância do papel da odontologia na prevenção da transmissão do coronavírus durante a pandemia de COVID-19, o atendimento clínico requer medidas de redução do risco de infecções. Faz-se necessária a adequação dos procedimentos padrão, a partir de diretrizes que estão sendo propostas e/ou intensificadas (VITOR GP, 2020). O contexto da pandemia do coronavírus pressupõe a necessidade de revisitar os princípios da biossegurança, norteadores da prática odontológica, e conhecer as particularidades impostas por um vírus até então desconhecido (MORALES-NAVARRO D, 2020).

Os cuidados com a prevenção da infecção cruzada nos consultórios odontológicospodem impedir que o vírus se propague (LI Z e MENG L, 2020). Definem-se, por isso, rígidos protocolos de biossegurança, que incluem uso de Equipamentos de Proteção Individual (EPI), lavagem das mãos antes e após o atendimento, bochechos com peróxido de hidrogênio a $1 \%$ e lodopovidona a $0,2 \%$, prévios ao tratamento (TUÑAS ITC, et al., 2020).

Percebe-se que existem diversas recomendações de protocolos clínicos direcionados ao enfrentamento da pandemia do coronavírus. Entretanto intui-se também a presença, às vezes sutil, de uma matriz ética a sustentar tais protocolos, correspondendo à missão quecumpre à Ética: não só buscar o critério para a avaliação das ações a designar como boas, senão ainda atualizá-lo no próprio agir quotidiano (RICOUER $P$, 1990). Desta forma, o uso rigoroso de protocolos de biossegurança correspondeao efetivo cuidado ético com o paciente e com a equipe de profissionais odontológicos, em ordem à ação boa (RICOUER P, 1990).

Ao se tratar dos cuidados com a prevenção ao coronavírus de maneira mais ampla, sob o ponto de vista da ética, alguns requisitos são inerentes e indispensáveis à atividade do profissional, tornando-o responsável pelos cuidados consigo e com aquele que é cuidado. A esta responsabilidade entende-se predisposição ao preparo adequado para o exercício da atividade a que se propõe, ao oferecer o que há de melhor, tornandose competente para tal tarefa (WERNECK RR, 2017).

Neste contexto, verificou-se que existem duas abordagens diante de situações difíceis, como a enfrentada diante da COVID-19: uma centrada na competência científica e técnica, que preconiza um rol de itens, a compor protocolos e condutas de combate ao coronavírus (TUÑAS ITC, et al., 2020); outra motivada pela competência ética, mais genérica e mais abrangente, porém aparentemente balizadora, por fundamentar tomadas de decisão importantes (WERNECK RR, 2017).

Diante deste cenário desafiador para a comunidade científica, empreendeu-se ampla busca na literatura, não tendo sido encontrado nenhum trabalho que abordasse a COVID-19 sob ambos os pontos de vista (competência técnica e competência ética). A relevância deste duplo enfoque ganha maior valor frente àpossibilidade de se estabelecer uma matriz ética que sustente os protocolos, de forma a não se tornar 0 atendimento meramente técnico, impessoal e sobretudo desumano. Neste contexto, objetivou-se com esta revisão verificar se os protocolos de combate à COVID-19 incluem uma matriz ética subjacente às condutas recomendadas aos profissionais de odontologia na prática clínica.

\section{REVISÃO BIBLIOGRÁFICA}

\section{Fundamentação teórica da Ética Profissional}

A Ética é o desígnio pessoal de uma vida consumada sob o signo das ações estimadas como boas. Neste sentido, ela mantém a sua relação com a atividade filosófica e com a vida quotidiana, na medida em que tem por missão não só buscar o critério para a avaliação das ações a designar como boas, senão também atualizálo no próprio agir quotidiano (RICOUER P, 1990).

Na própria expressão do autor, à Ética cumpre "visar o bem, vivendo com e para os outros em instituições justas", implica também uma vida examinada, na dimensão racional e na capacidade de decisão pessoal, simultâneas a um reconhecimento da comunidade e do sentido da vida humana. Por outro lado, visar o bem corresponde a afirmar o bem como finalidade da vida humana, isto é, postular a existência de um bem que transcende a ação individual, tendo, por isso, um carácter teleológico de que decorre o normativo (RICOUER $P, 1990)$. 
Somente esta perspectiva global da Ética pode dar suporte à ética profissional, a qual, por sua vez, também embasa a profissão em termos da consciência e do fazer o bem, permitindo vias de resposta a perguntas tais como: o que é ser bom profissional? Em que consiste fazer o bem no exercício profissional, raciocinando, abrindo possibilidades optativas? Uma ética profissional, portanto, também a ética profissional dos odontologistas, sendo uma ética especial e não apenas aplicada, visa orientar, justificar ou questionar as atuações e decisões específicas do âmbito de atividade em apreço - no caso, a odontologia. Diz-se que é uma ética especial uma vez que as exigências e recomendações de nível geral se revelam insuficientes, por inespecíficas, para dar resposta aos problemas éticos da profissão (HORTAL A, 2002).

No âmbito da ética médica e da Saúde, são geralmente citados como fundamento para a tomada de decisão os quatro princípios biomédicos Beneficência, Autonomia, Justiça e Não Maleficência. Estes princípios podem oferecer um referencial básico no momento de formar juízo em situações envolvendo a saúde-doença, como é o caso diante da pandemia de COVID-19. Esta orientação principialista tem como fundamento o respeito pelos direitos individuais, o valor da justiça e a reciprocidade de direitos e deveres. Eles trazem, por isso, elementos dos quais não é possível prescindir no momento de formar o juízo moral na atuação profissional, nomeadamente na área de saúde, como é o caso da odontologia (BEAUCHAMP TL e CHILDRESS JF, 1984).

Por outro lado, em confronto com esta perspectiva, tem vindo a afirmar-se uma orientação não principialista, que parte da verificação da vulnerabilidade de cada um dos sujeitos sofredores e aprecia e caracteriza o cuidado necessário para a superação ou a aceitação de dita vulnerabilidade. Esta orientação não é uniforme e inclui pensadores com orientações filosóficas tão variadas como Boff, Pelegrino ou Kemp.

\section{Matriz Ética nos protocolos de enfrentamento à COVID-19 no atendimento odontológico}

Toda ação humana deve estar orientada para a execução de algum bem (ARISTÓTELES, 1973). E assim como cada indivíduo se interroga no seu agir quotidiano sobre a parcela de bem das suas ações, assim também em cada coletivo profissional a dimensão ética corresponde a se perguntar constantemente: qual a nossa contribuição ao bem comum? (HORTAL A, 2002).

Neste sentido, diante da pandemia de COVID-19, são recomendadas medidas de controle de infecção durante a prática odontológica para bloquear as rotas de transmissão de pessoa para pessoa em clínicas e hospitais (XIAN P, et al., 2020). As condutas e os métodos recomendados estão inseridos no Quadro 1. A questão que se-nos ocupa diante dessas condutas e métodos é verificar se eles incluem uma matriz ética, isto é, se os profissionais de odontologia estão conscientes de que desempenham grande papel na prevenção da COVID-19 e de que as suas condutas e protocolos são relevantes para o bem comum.

A análise das medidas de controle de infecção adotadas revelou uma matriz ética na conduta, ao fazer referência ao princípio da Não Maleficência. Esse princípio tem como enunciado mais universal: "Primum non nocere", isto é, estabelece a obrigação de não infligir intencionalmente um possível dano ao outro. Este princípio foi seguido de forma evidente no primeiro momento do confinamento em que os cirurgiões-dentistas pararam toda a atividade em ordem a não prejudicar os seus pacientes (WERNECK RR, 2017).

Com efeito, para deixar de fazer algo por acreditar que possa causar mal a alguém, é necessário contar somente com a própria apreciação; para deixar de fazer, não é necessário nenhum recurso nem levar em consideração as circunstâncias. Esta era a situação real no início da pandemia, em que o conhecimento disponível sobre o vírus era muito reduzido e os profissionais apenas podiam contar com o seu próprio juízo. Porém, o inevitável aparecimento de situações de urgência implicou a reapreciação deste modo de atuar: fazer o bem é sempre algo mais relativo, ao passo que não fazer o mal é absoluto (WERNECK RR, 2017).

Quando se dedica a entender o que, numa situação concreta, nomeadamente numa situação de urgência, pode causar dano, maior ou menor, em termos físicos, psíquicos, emocionais ou sociais, há que se dedicar a saber que bens merecem ser promovidos ou, pelo menos, não prejudicados (WERNECK RR, 2017). Esse é o momento do confronto entre as atuações mais diretamente decorrentes dos princípios da não maleficência, da beneficência e da justiça. 
Martins-Filho PR, et al. (2020), ao confirmarem que o coronavírus é transmitido principalmente por gotículas, espirros e aerossóis, e que há um alto risco de transmissão durante os procedimentos odontológicos, elaboraram relatório que descreve os passos que podem ser tomados pelo pessoal de saúde bucal para minimizar o risco de contaminação cruzada na prática clínica (Quadro 1).

Quadro 1 - Condutas e métodos de controle de infecção na clínica odontológica.

\begin{tabular}{|c|c|}
\hline Conduta & Método \\
\hline $\begin{array}{l}\text { Triagem prévia dos } \\
\text { pacientes }\end{array}$ & Fazer contato por telefone, e-mail, whatss-App ou outro meio eletrônico \\
\hline Medir a temperatura & Utilizar termômetro sem contato \\
\hline \multirow{7}{*}{$\begin{array}{l}\text { Aplicar questionário prévio à } \\
\text { consulta }\end{array}$} & Teve febre nos últimos 14 dias? \\
\hline & Teve tosse nos últimos 14 dias? \\
\hline & Teve dificuldade de respirar nos últimos 14 dias? \\
\hline & Viajou para cidades com transmissão documentada nos últimos 14 dias? \\
\hline & $\begin{array}{l}\text { Entrou em contato com paciente com infecção confirmada ou } \\
\text { suspeitanos últimos } 14 \text { dias? }\end{array}$ \\
\hline & Participou recentemente de alguma reunião ou teve contato \\
\hline & próximo com muitas pessoas desconhecidas? \\
\hline $\begin{array}{l}\text { Preparar a equipe de saúde } \\
\text { bucal }\end{array}$ & Como usar EPI \\
\hline Desinfetar as mãos & Usar água e sabão, etanol ou isopropanol a $70 \%$ \\
\hline $\begin{array}{l}\text { Preterir radiografias } \\
\text { intrabucais }\end{array}$ & $\begin{array}{c}\text { Priorizar radiografias panorâmicas, evitando o contato com a cavidade } \\
\text { bucal }\end{array}$ \\
\hline Usar isolamento absoluto & O lençol de borracha restringe o contato com a cavidade bucal \\
\hline \multirow{2}{*}{ Evitar geração de aerossóis } & Restringir uso de ultrassom, seringa tríplice, polimento a ar, unidades \\
\hline & de abrasão a ar e peças de mão rotativas. \\
\hline Gerenciar resíduos & Usar embalagens específicas para resíduos infectados \\
\hline \multirow[t]{2}{*}{ Gerenciar atendimentos } & $\begin{array}{l}\text { Deixar casos suspeitos de COVID-19 para final de turno - evita contato } \\
\text { entre pacientes }\end{array}$ \\
\hline & Intervalo maior entre as consultas - evita contato entre pacientes \\
\hline
\end{tabular}

Fonte: Martins-Filho PR, et al., 2020; Silva Filho PSP, et al., 2020; Xian P, et al., 2020. Dados coletados por Werneck RR, et. al., 2020.

Ao verificar a gravidade desta pandemia, o Conselho Regional de Odontologia de Minas Gerais (CROMG) editou resolução que orienta os cirurgiões-dentistas quantoa procedimentos para evitar a disseminação da COVID-18, a saber: utilização, por parte dos pacientes, de máscara de proteção na sala de espera e áreas comuns dos estabelecimentos odontológicos; disponibilização para os pacientes, funcionários e colaboradores de recursos necessários à higienização pessoal na recepção, em especial álcool na concentração de 70\% (CONSELHO REGIONAL DE ODONTOLOGIA DE MINAS GERAIS, 2020).

O CROMG ainda recomendou o espaçamento mínimo de dois metros entre as pessoas que aguardam atendimento; controle da entrada de pacientes, seja por barreira física, agendamento prévio por telefone ou por outro sistema eletrônico; realização de triagem dos pacientes anteriormente ao atendimento presencial; aferição da temperatura em local reservado, evitando que o paciente circule pelas áreas comuns do consultório, e preferencialmente utilizando termômetro que dispense o contato físico; observação do tempo de intervalo mínimo de trinta minutos entre os pacientes, realizar uma desinfecção minuciosa dos ambientes; e esterilização das canetas de alta e baixa rotação, além do isolamento do profissional que contrair a COVID19 (CONSELHO REGIONAL DE ODONTOLOGIA DE MINAS GERAIS, 2020). 
O CROMG oferece, pois, orientação pormenorizada aos cirurgiões-dentistas, quanto ao atendimento dos pacientes, organização do espaço e medidas de higiene antes, durante e após o atendimento. Porém, não apresenta uma justificação ética para essas orientações. Será possível identificar uma matriz ética que suporte estas orientações? Em nosso entender, é possível verificar uma matriz ética nesta conduta do CROMG, não explícita, mas alinhada com o Princípio da Beneficência (GARCíA D, 2008).

Com efeito, embora à primeira vista pareça marcado por uma conotação assistencialista e paternalista por estabelecer orientações universais de proteção do paciente, ao invés de promover a avaliação individual do profissional sobre a sua conduta, essas orientações do CROMG pressupõem uma matriz ética, que estabelece o dever de competência pelo qual todos os profissionais são obrigados a fazer bem o que fazem, integrando assim o saber científico como parte do critério ético para ajuizar da beneficência e da não maleficênciana conduta profissional (HORTAL A, 2002).

Em consonância com o CROMG, a compilação de protocolos recomendados pelas autoridades de saúde revelou que as principais recomendações incluem triagem de pacientes, distanciamento social, ajustes nos EPI e uso de produtos e técnicas de desinfecção apropriados, que provavelmente permanecerão após 0 período de pandemia (MORALES-NAVARRO D, 2020). Por outro lado, é possível identificar um conjunto de preocupações que emergem da consideração da dimensão pessoal, tanto do paciente como dos profissionais de odontologia.

$\mathrm{Na}$ verdade, a falta de direcionamento formalizado para o profissional acarreta medo e dificuldade para a realização do tratamento odontológico. A pandemia de COVID-19 promoveu mudanças na Odontologia, ocasionando uma alteração expressiva na forma de atendimento e da rotina dos consultórios. Conhecimentos sobre infecção cruzada, infecções respiratórias, formação de aerossóis e biossegurança devem fazer parte do cotidiano a partir de agora. No entanto, a alteração frequente de protocolos origina insegurança e medo, não só do lado da comunidade, como também dos próprios profissionais. Daí a necessidade de que os profissionais de odontologia se apoiem mutuamente, tanto o cirurgião-dentista, quanto os pacientes e a equipe auxiliar, de forma a dividir as aflições, as soluções, os fluxogramas e proporcionar segurança para a continuidade das atividades (FRANCO JB, 2020).

Por outro lado, a recomendação de proceder ao alívio sintomático do paciente com dor e / ou edema, a ser realizado com analgésicos, e o adequado descarte de resíduos resultantes dos procedimentos odontológicos, em função de os mesmos oferecerem risco à saúde da coletividade e à ecologia, revela cuidado ético, mesmo que sem referência explícita à proposta conhecida como ética do cuidado (MARTINSFILHO PR, et al., 2020).

A atual pandemia da COVID-19 obrigou os cirurgiões-dentistas de todo o mundo a formular novas diretrizes de atendimentos. Silva R, et al. (2020), por meio de pesquisa documental comparativa dos protocolos formulados em quatro países do Mercado Comum do Sul (MERCOSUL), analisaram as principais semelhanças nas orientações propostas. Os resultados apresentaram semelhanças quanto ao uso de EPI, métodos de antissepsia e limpeza. No entanto, houve diferença quanto aos intervalos de tempo entre as consultas.

Alguns aspectos dos protocolos foram relatados de forma superficial e outros nem foram mencionados. Neste contexto de falta de unidade concluiu-se que é necessária orientação detalhada acerca das medidas a serem adotadas pelos profissionais da odontologia, e que de fato sejam efetivadas. Reforça-se ainda a necessidade de atualização constante dos protocolos, com base nas evidências científicas mais recentes.

Em meio às condutas e protocolos técnicos, mais um achado relacionado à ética contido nos protocolos é desvelado a seguir: o cirurgião-dentista deve realizar com frequência a lavagem das mãos antes e após o atendimento, usar EPI, além de fazer bochechos com peróxido de hidrogênio a $1 \%$ e lodopovidona a $0,2 \%$, prévios ao tratamento. A clorexidina a $0,12 \%$, prescrita com frequência na prática clínica, não apresenta efetividade no combate ao coronavírus. Diante de novos desafios, como o que se apresenta, há que se atentar aos cuidados relativos à biossegurança, à ética, ao zelo e ao treinamento atualizado e periódico (TUÑAS ITC, et al., 2020). 
Os cuidados com a biossegurança reportam ao princípio biomédico da Não Maleficência (BEAUCHAMPS TL e CHILDRESS JF, 1984). O zelo reporta à ética do cuidado (BOFF L, 1999). O treinamento atualizado e periódico reporta à competência ética (CECCIM RB, 2018). O princípio de Não Maleficência não introduz nenhuma temática que já não tenha sido trazida pelos outros princípios, mas o que importa em cada um deles é a sua maneira de relacionar-se com cada caso e cada situação, pois o que está em jogo é uma vida humana, sua dignidade, sua plenitude vivida por todos em justiça e liberdade (HORTAL A, 2002).

\section{Matriz Ética nas recomendações de EPI para proteção contra o coronavírus na prática clínica}

Ao serem referidas as máscaras como equipamento de proteção, percebe-se o cuidado ético, ao se reconhecer as limitações dos estudos relacionados à eficácia de cada uma (HORTAL A, 2002). Há evidências da maior eficácia das máscaras PFF2, N95 ou equivalente se comparadas à máscara cirúrgica em ambientes laboratoriais e em procedimentos geradores de aerossóis, porém os resultados de estudos clínicos são inconclusivos em relação às infecções respiratórias agudas (MARTINS-FILHO PR, et al., 2020).

Quanto ao uso das máscaras de TNT (tecido não tecido), existe potencial benefício dessa prática, entretanto, diante da pandemia de COVID-19, é necessário educar o usuário quanto ao seu uso adequado, assim como em todas as outras, além de associar sua utilização a medidas individuais de proteção (LIMA A, et al., 2020).

Há que se atentar para as evidências científicas de que as máscaras cirúrgicas e as máscaras de tecido são recomendadas somente quando não há produção de aerossóis, destacando-se que a eficácia e a segurança destas máscaras indicam que este EPI possibilita uma barreira física às gotículas emitidas pela fala ou tosse, entretanto seu uso não é totalmente eficiente, mesmo que seja um recurso adicional na prevenção do coronavírus (TAMINATO M, et al., 2020);

O cuidado e a preocupação com o uso correto das máscaras, a avaliação do benefício que esta prática pode proporcionar e a análise da eficiência deste EPI reportam à ética do cuidado, ao Princípio Biomédico da Beneficência e à competência ética (BOFF L, 1999; BEAUCHAMP TL e CHILDRESS JF, 1984; CECCIM $\mathrm{RB}, 2018)$.

O correto uso de luvas, como forma de evitar infecções cruzadas e ação de agentes biológicos e químicos; dos óculos, como proteção contra secreções e aerossóis provenientes dos procedimentos; dos propés, como barreiras físicas contra a dispersão de contaminantes da clínica para o meio externo; dos gorros ou tocas; dos aventais e protetores faciais remetem à ética profissional (SARMENTO LC, et al., 2020).

Para apreciar que espécie de bem buscam os profissionais no exercício de sua atividade profissional, qualquer que ele seja, os profissionais devem ser competentes e responsáveis. Mas em que consiste essa competência? O que compete e o que não compete ao profissional? Quais as destrezas sem as quais sua atuação não mereceria ser qualificada como profissional? A ética profissional não consiste em impor regras que permitam a convivencia sem que um cause daño ao outro, mas sim no descobrimento ou na elaboração de metas, valores e convicções que se possa compartilhar ou desfrutar em companhia dos pares, isto é, a ética, num sentido constitutivamente social, refere-se finalmente à consciência das pessoas (HORTAL A, 2002).

\section{CONSIDERAÇÕES FINAIS}

Os protocolos de combate à COVID-19 revelaram-se eminentemente técnicos, baseados em condutas e diretrizes contra possível infecção dos profissionais e pacientes. Entretanto, foi possível também perceber preocupações voltadas aos princípios da Beneficência e da Não Maleficência, tal como definido por Beauchamp e Childress, os quais se inscrevem numa ética da justiça, havendo também referência ao zelo com o outro e à solidariedade entre os profissionais, potencialmente próximos de uma ética do cuidado. Se bem que não possam ser consideradas como reveladoras de uma matriz ética, certamente já demonstram sinais da preocupação ética na elaboração de condutas frente ao coronavírus. Há que se trabalhar mais o tema, de forma a estabelecer ligações de maior proximidade entre as competências técnica e ética, não só especificamente relacionadas com a pandemia atual, mas presentes em toda a atuação dos profissionais de odontologia. 


\section{AGRADECIMENTO}

Ao professor Wellington Krepke Duarte, pela revisão gramatical deste artigo.

\section{REFERÊNCIAS}

1. ARISTÓTELES. Ética a Nicômaco. Trad. de Leonel Vallandro e Gerd Bornheim da versão inglesa de W. D. Ross. Col. Os pensadores. São Paulo: Editora Abril Cultural, 1973; 375p.

2. BEAUCHAMP TL, CHILDRESS JF. Respect for autonomy, nonmaleficence, beneficence, justice. In: Beauchamp T. L.; Childress J. F., editors. Principles of biomedical ethics. (4르 ed.). New York: Oxford University Press;1994; $120-392$.

3. BOFF L. Saber cuidar: ética do humano. Rio de Janeiro: Vozes, 1999; 12p.

4. CECCIM RB. Réplica sobre adaptação, resistência e competência ética na interprofissionalidade. Interface, Botucatu, 2018; 22 supl. (2): 1760-1762.

5. CONSELHO REGIONAL DE ODONTOLOGIA DE MINAS GERAIS. Resolução CRO-MG № 007/2020. Dispõe sobre normas de controle ao contágio pelo Coronavírus, sob o aspecto ético disciplinar, no âmbito da Odontologia e dá outras providências. Belo Horizonte, 2020. Disponível em: https://transparencia.cromg.org.br/baixar_documento/17791.

6. DUARTE PM. COVID-19: Origem do novo coronavírus. Brazilian Journal of Health Review, 2020; 3(2): 3585-3590.

7. FRANCO JB. Cuidados Odontológicos na era do COVID-19: recomendações para procedimentos odontológicos e profissionais. REV ASSOC PAUL CIR DENT, 2020; 74(1): 18-21.

8. GARCÍA DE. Ética, profesión y ciudadanía. Una ética cívica para la vida em común. México D. F.: Porrúa, 2008; 196p.

9. HAO X, et al. High expression of ACE2 receptor of 2019-nCoV on the epithelial cells of oral mucosa. Int J Oral Sci, 2020; 12(1): 1-5.

10. HORTAL A. Ética General de lasprofesiones. Bilbao: Desclée de Brower, 2002; 284p.

11. LI Z, MENG L. Prevention and control of new coronavirus infection in oral diagnosis and treatment. Chin J Stomatol, 2020; 55(4): E001-E001.

12. LIMA A, et al. Eficácia da máscara facial (TNT) na população para prevenção de infecções por coronavírus: revisão sistemática. SciELO Preprints, 2020.

13. MARTINS-FILHO PR, et al. Recommendations for a safety dental care management during SARS-CoV-2 pandemic. Rev PanamSalud Publica, 2020; 44(e51): 1-4.

14. MORAES DC, et al. Dental care in COVID-19 times: sharing good protective and biosafety practices. Journal of Dentistry \& Public Health, 2020; 11(1): 73-82.

15. MORALES-NAVARRO D. Riesgos y retos para los profesionales de las disciplinas estomatológicas ante la COVID19. Revista Habanera de Ciencias Médicas, 2020; 19(2):1-18.

16. OLIVEIRA JJM DE, et al. O impacto do coronavírus (covid-19) na prática odontológica: desafios e métodos de prevenção. Revista Eletrônica Acervo Saúde, 2020; 46: e3487.

17. PENG S, et al. PreventionandControlofthe Novel Coronavirus in theStomatological Hospital. European Journal of Preventive Medicine, 2020; 8(2): 12-15.

18. RICOUER P. Soi-même comme un autre. Paris: Le Seuil, 1990; 432p.

19. SARMENTO LC, et al. Uso do Equipamento de Proteção Individual (EPI) na Odontologia frente a COVID-19. Portal.ufes.br, 2020; 1: 1-12.

20. SILVA FILHO PSP, et al. The importance of using individual protection equipment (IPE) in times of covid-19. Research, Society andDevelopment, 2020; 9(7): e629974610.

21. SILVA R, et al. Protocolos de atendimento odontológico durante a pandemia de COVID-19 nos países do MERCOSUL: similaridades e discrepâncias. Vigilância Sanitária em Debate: Sociedade, Ciência \& Tecnologia, 2020; 8(3): 1-8.

22. TAMINATO M, et al. Máscaras de tecido na contenção de gotículas respiratórias - revisão sistemática. Acta paul. enferm., 2020; 33:eAPE20200103.

23. TUÑAS ITC, et al. Doença pelo Coronavírus 2019 (COVID-19): Uma abordagem preventiva para Odontologia. BrazilianJournalofDentistry, 2020; 77: e1766.

24. VITOR GP. Atendimento clínico odontológico durante covid-19: medidas de redução do risco de infecções. J. Infect. Control, 2020; 9(2): 1-4.

25. WERNECK RR, et al. Dimensão ética nas faculdades de odontologia no Brasil: por que desenvolvê-la? Afluente: Revista de Letras e Linguística. UFMA/Campus III, 2018; 3(7): 46-62.

26. WERNECK RR. A dimensão ética na formação dos Cirurgiões-Dentistas no Estado de Minas Gerais - Brasil. Tese (Doutorado em Ciências da Educação) - Universidade de Trás-os-Montes e Alto Douro, Vila Real, Portugal, 2017; $281 \mathrm{p}$.

27. WORLD HEALTH ORGANIZATION (WHO). Report of the WHO-China Joint Mission on Coronavirus Disease 2019 (COVID-19). 2020. Disponível em: https://www.who.int/emergencies/diseases/novel-coronavirus2019?gclid=EAlalQobChMI4d_uu_y26wIVEQiRCh1utQTaEAAYASAAEgIYvPD_BwE. Acessoem: 21 ago. 2020.

28. XIAN P, et al. Transmission routes of n2019-nCoV and controls in dental practice. Int J Oral Sci, 2020; 12(1): 1-6. 